\section{Erradicação da poliomielite no Brasil: a contribuição da Fundação Oswaldo Cruz}

\author{
Eradication of \\ poliomyelitis in \\ Brazil: the
} contribution

of Fundação Oswaldo Cruz
SCHATZMAYR, H. G.; FILIPPIS, A. M. B. de; FRIEDRICH, F. e LEAL, M. da L. F.: 'Erradicação da poliomielite no Brasil: a contribuição da Fundação Oswaldo Cruz'.

História, Ciências, Saúde-Manguinhos, Rio de Janeiro, vol. 9(1): 11-24, jan.-abr. 2002.

A erradicação dos vírus selvagens da poliomielite nas Américas constituiu um marco notável da saúde pública no continente americano. A Fundação Oswaldo Cruz (Fiocruz) contribuiu de forma decisiva para este resultado de várias formas, como o apoio laboratorial do Centro Nacional de Enteroviroses, do Departamento de Virologia do Instituto Oswaldo Cruz, a formulação e o fornecimento da vacina oral por Bio-Manguinhos, o apoio laboratorial e epidemiológico da Escola Nacional de Saúde Pública e o controle das vacinas pelo Instituto Nacional de Controle da Qualidade em Saúde. A Fiocruz também desenvolveu importantes projetos de pesquisa em enterovírus. Sendo a poliomielite ainda um problema para vários países do mundo, é oportuno relatar a importância do trabalho realizado pela Fiocruz para a erradicação da doença no Brasil e nas Américas.

PALAVRAS-CHAVE: poliomielite, erradicação da poliomielite, vacina Sabin, epidemiologia da poliomielite, diferenciação intratípica de poliovírus.

SCHATZMAYR, H. G.; FILIPPIS, A. M. B. de; FRIEDRICH, F. e LEAL, M. da L. F.: 'Eradication of poliomyelitis in Brazil: the contribution of Fundação Oswaldo Cruz'.

História, Ciências, Saúde - Manguinhos, Rio de Janeiro, vol. 9(1): 11-24, Jan.-Apr. 2002.

The eradication of wild polioviruses from the Americas represents a remarkable public Health achievement. Oswaldo Cruz Foundation (Fiocruz) contributed to this result in many ways. Its National Reference Center for Enteroviruses in the Department of Virology of Oswaldo Cruz Institute developed laboratory activities, Bio-Manguinhos developed and delivered the oral vaccine, its National School of Public Health developed epidemiological and laboratory activities and its National Institute for Quality Control in Health controlled the vaccine. Fiocruz also carried out important research projects on enteroviruses. Since poliomyelitis still represents a serious problem in many countries in the world, it is important to emphasize the relevant contribution of Fiocruz to the eradication of the disease in Brazil and in the American continent.

KEYWORDS: poliomyelitis, poliomyelitis eradication, poliomyelitis in Brazil, poliomyelitis epidemiology, Sabin oral vaccine, poliovirus intratypic differentiation.

Maria da Luz Fernandes Leal

Bio-Manguinhos, Fundação Oswaldo Cruz 
$\mathrm{E}$ m 29 de setembro de 1994, o Brasil recebeu da Organização Pan-Americana de Saúde (Opas) o certificado de interrupção da transmissão dos vírus selvagens da poliomielite no Brasil, confirmando a conclusão da comissão nacional que havia anteriormente declarado o país livre desses vírus.

Esse feito foi a conclusão de uma longa luta contra a doença, que se estendeu por várias décadas, mobilizou mais de uma geração de profissionais da área da saúde em todo país e, por fim, a própria sociedade brasileira, por meio das grandes campanhas nacionais de vacinação que ainda hoje ocorrem a cada ano.

No presente artigo, relatamos as principais atividades do combate à poliomielite das quais a Fiocruz participou e que envolveram sobretudo o Instituto Oswaldo Cruz (IOC), Bio-Manguinhos, a Escola Nacional de Saúde Pública (ENSP) e o Instituto Nacional de Controle da Qualidade em Saúde.

\section{A poliomielite no Brasil}

Embora existam referências de casos esporádicos de quadro clínico semelhante ao da poliomielite no final do século XIX (Lima Filho et al., 1993), essa doença começou a ser mais bem observada no país no início do século XX, no Rio de Janeiro (1907-11) e em São Paulo (1918) (Scorzelli, 1966). Surtos de considerável magnitude foram observados na década de 1930, em Porto Alegre (1935), Santos (1937), São Paulo e Rio de Janeiro (1939), refletindo possivelmente a crescente urbanização do país.

A partir de 1950, foram descritos surtos em diversas cidades do interior, e, em 1953, ocorreu no Rio de Janeiro a maior epidemia já registrada, atingindo o coeficiente de 21,5 casos por cem mil habitantes (Scorzelli, 1966). Apesar da precariedade dos dados disponíveis, Ayroza-Galvão et al. (1955), revelaram a importância crescente da doença no país. Os dados sobre a poliomielite no Rio de Janeiro, entre 1907 e 1974, foram revisados por von Hubinger (1975).

A primeira vacina desenvolvida contra a poliomielite por Jonas Salk, no início da década de 1950, e que foi capaz de reduzir drasticamente o número de casos clínicos nos países em que foi empregada, não chegou a ser utilizada em ampla escala no Brasil. Na época, os altos custos e as dificuldades operacionais para aplicação em larga escala de produto injetável acabaram adiando o uso da vacina entre nós. No final da mesma década, iria surgir a vacina oral, criada principalmente por Albert Sabin.

As vacinações sistemáticas contra a poliomielite foram introduzidas na rotina dos serviços de saúde pública do Brasil, em 1960, na cidade de Petrópolis (RJ). Nesse plano piloto, foi utilizada apenas a vacina monovalente, contendo o sorotipo 1 , seguida de duas doses trivalentes 
(sorotipos 1, 2 e 3). Tal esquema de vacinação não foi adotado posteriormente, preferindo-se usar apenas vacinas trivalentes. Os programas de imunização não tiveram, entretanto, a abrangência e a continuidade necessárias para o controle da doença, o que resultou na permanência da poliomielite como um importante problema de saúde pública no país (Meilman et alii, 1988).

As principais razões para esse fato foram a curta duração da validade da vacina, naquela ocasião - a qual necessitava ser aplicada dentro de uma semana após ser envasada —, e a importação do produto não apenas por parte do governo federal como também, de maneira direta, por alguns estados, o que dificultava o controle adequado da qualidade de todas as vacinas adquiridas.

Dados nacionais sobre a incidência da doença, disponíveis a partir de 1968, quando foi implantado um sistema de notificação semanal de várias doenças transmissíveis, inclusive a poliomielite, indicavam, até 1980, entre 1.100 e 3.600 casos anuais de poliomielite. O problema tornava-se ainda mais grave pela ocorrência freqüente de surtos em diversos pontos do território nacional, gerando uma forte demanda de serviços de saúde e a presença de seqüelas paralíticas graves provocadas pela doença, com alto impacto social.

Em 1971, na tentativa de interromper a transmissão da doença, o Ministério da Saúde elaborou o Plano Nacional de Controle da Poliomielite. O plano estabelecia a vacinação em massa da população infantil, com a aplicação de três doses de vacina oral trivalente, com intervalos de seis a oito semanas entre cada uma delas, na faixa etária de três meses a quatro anos de idade, que havia sido identificada como a mais susceptível de apresentar a doença. A vacina deveria ser aplicada simultaneamente em todos os estado, nas áreas urbanas com mais de dois mil habitantes (idem, ibidem).

Os resultados obtidos foram, mais uma vez, piores do que se esperava, sobretudo pelas coberturas vacinais muito irregulares de estado a estado. Uma investigação epidemiológica realizada no período de 1975 a 1976, incluindo 1.643 casos procedentes de 18 estados, mostrou que as principais características da doença no país, naquele momento, eram sua distribuição predominantemente urbana (74\%), a concentração em menores de cinco anos, uma elevada proporção de casos em crianças não vacinadas (76\%), a predominância do poliovírus do sorotipo 1 (87\%) e uma elevada letalidade (idem, ibidem).

Confirmando as falhas do programa, quase todos os estados brasileiros notificaram surtos de poliomielite no período de 1975 a 1979. Por essa razão, estabeleceu-se um novo plano de ação para o período de 1980 a 1984 (Risi, 1984). A base desse plano era a criação de dois dias nacionais de vacinação em massa, empregando-se a cada ano a vacina oral, a fim de se alcançar, a cada vez, alta cobertura vacinal em todas as regiões brasileiras em um único dia e, com isso, 
interromper a circulação do vírus selvagem, pela ampla disseminação do vírus vacinal em todo país. Tendo em vista que 91,5 \% dos casos de poliomielite ocorriam, naquela ocasião, em crianças abaixo de quatro anos de idade, todas as crianças dentro dessa faixa etária foram convocadas a receber a vacina, sem se levar em conta sua prévia história de imunização contra a poliomielite.

Os dias nacionais de vacinação foram capazes de mobilizar grandes segmentos da sociedade e alcançaram êxito excepcional. Analisando-se os dados do período de outubro de 1980 a setembro de 1982, observa-se o registro de apenas oito casos em média por mês, quando a incidência de 1975 a 1980 alcançou entre cem a quinhentos casos mensais, com uma média anual de 2,1 casos por cem mil habitantes.

Em 1982, apenas 122 casos de poliomielite foram registrados no país, o que representou a incidência de 0,1 caso por cem mil habitantes (Risi, 1984). Nos dois anos seguintes (1982 e 1983), a redução no número de casos foi ainda maior, o que demonstrava que os oito dias nacionais de vacinação até então executados, e que alcançaram coberturas próximas a 100\%, haviam possibilitado, pela primeira vez, o real controle da infecção no país.

Uma queda no percentual de cobertura vacinal foi observada durante os anos de 1984 até a segunda metade de 1986, em relação aos anos anteriores. O número de casos voltou imediatamente a elevar-se para 142, em 1984; no ano seguinte, a queda do percentual de cobertura vacinal acentuou-se, decaindo para apenas $80 \%$, o que resultou no aumento do número de casos para 329, em 1985, e 612, em 1986. O fator mais importante para essas quedas de cobertura vacinal parece ter sido a crença de que a poliomielite já havia sido controlada em definitivo, além de problemas operacionais nas campanhas de vacinação nesses anos, quando se tentou a vacinação contra outras doenças no mesmo dia da vacinação oral, o que gerou sérias dificuldades no plano local.

No período de fevereiro a julho de 1986, um novo problema surgiu, com a ocorrência de uma epidemia de poliomielite na região Nordeste, provocada pelo sorotipo 3. Um estudo sorológico realizado em crianças vacinadas da região demonstrou um baixo nível de anticorpos para esse sorotipo, o que certamente contribuiu para a dispersão do vírus tipo 3 na região e para a formação da epidemia (Patriarca et alii, 1991).

Essa baixa resposta de anticorpos havia sido observado por nosso grupo em outros países e também no Brasil. Demonstrou-se claramente a necessidade de aumentar-se a quantidade de vírus do sorotipo 3 na formulação da vacina, em um trabalho anteriormente realizado no estado do Espírito Santo, com o apoio da então Fundação Sesp (Brito Bastos et alii, 1974). Nossa informação, contudo, não foi levada em consideração. Somente após a epidemia no Nordeste, a quantidade de vírus do tipo 3 
na vacina passou a ser de seiscentas mil partículas infectantes, o dobro da dosagem anterior.

A partir do segundo semestre de 1986, considerando-se os problemas específicos do Nordeste, foi instituída mais uma campanha anual de vacinação (Figura 1 ) limitada àquela região, o que resultou na queda do número de casos, para 197, em 1987. Nos anos seguintes, ainda foram observados casos na região Nordeste, sobretudo em áreas urbanas com baixo nível de saneamento básico, até que foram notificados, finalmente, os três últimos casos de poliomielite causados por vírus selvagens, nos estados do Rio Grande do Norte e da Paraíba, no ano de 1989. O último caso de poliomielite causado por esse tipo de vírus no Brasil ocorreu no município de Sousa, na Paraíba, tendo a paralisia se iniciado a 19 de março daquele ano. Nas Américas, o último caso ocorreu no Peru, com início da paralisia em 22 de agosto de 1991. Com isso, obteve-se a erradicação dos vírus selvagens da poliomielite de todo continente americano.

Figura I

Casos notificados de poliomielite e cobertura vacinal, Brasil, 1979-93

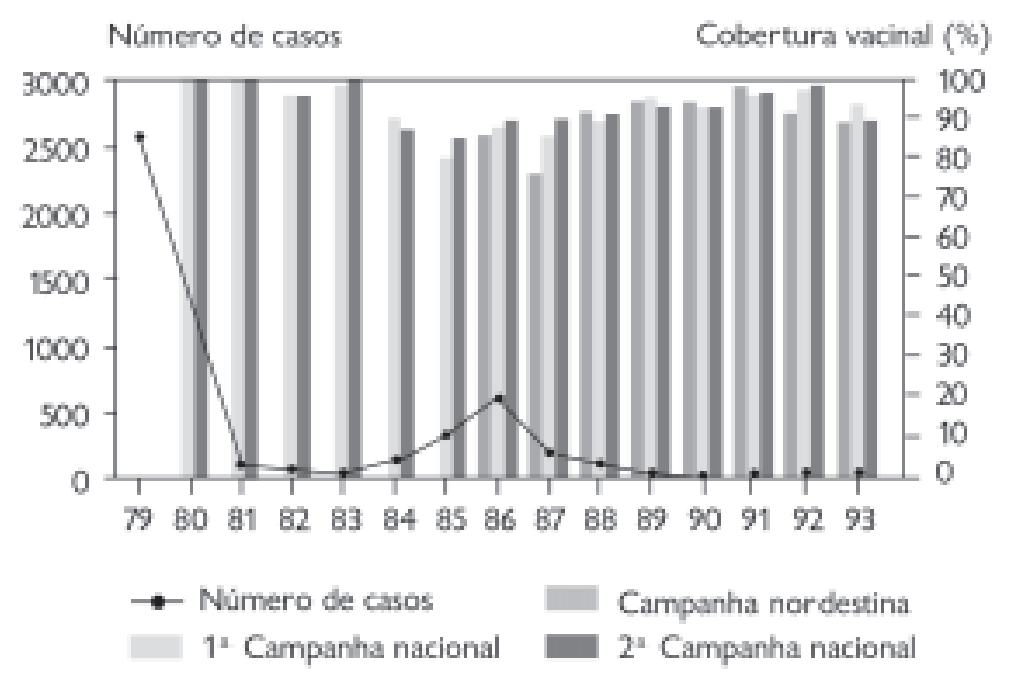

Fonte: GT-Pólio/CENEPI/FNS/MS

As campanhas nacionais de vacinação realizadas no Brasil, que chegam a alcançar cerca de 18 milhões de crianças em um único dia, serviram de modelo de trabalho para todo mundo, em especial para a Ásia e a África, onde ainda ocorrem casos clínicos com o vírus selvagem. Nesses continentes, os dias nacionais de vacinação — onde foi possível implantá-los - têm sido essenciais para se reduzir o impacto da doença, esperando-se alcançar, como nas Américas, a erradicação da poliomielite em futuro breve. 


\section{A contribuição da Fundação Oswaldo Cruz}

A descoberta, por Enders e colaboradores (1949), de que o vírus da poliomielite replicava em cultura de células não nervosas foi o passo fundamental para a produção das vacinas contra essa doença, tanto a inativada, desenvolvida por Jonas Salk, como a vacina viva oral, preparada sobretudo por Albert Sabin. Vacinas orais foram desenvolvidas por dois outros grupos de pesquisa, liderados por Cox e Koprowski, respectivamente, as quais, no entanto, não chegaram a ser usadas em larga escala.

O trabalho de Enders e colaboradores resultou na concessão do prêmio Nobel de Medicina ao grupo e permitiu não somente o preparo de vacinas como também que se estabelecesse o diagnóstico laboratorial de casos de poliomielite pelo isolamento de vírus em culturas de células, e não mais em primatas, o que viabilizou o estudo de grande número de casos em curto prazo.

Objetivando o estabelecimento de um grupo de estudo sobre enteroviroses no Brasil, a Opas, em 1960, por meio de um convênio com o IOC, montou um laboratório no Pavilhão Rockefeller, no campus de Manguinhos. O laboratório funcionou de forma muito ativa até 1964. Nessa fase, foram desenvolvidas novas metodologias de diagnóstico (Schatzmayr et alii, 1962) e estudos comparativos sobre a replicação de enterovírus dos grupos Coxsackie e ECHO em células e em camundongos (idem, 1965, 1964), que permitiram a implantação de projetos sobre o papel desses grupos de vírus em quadros de doença paralítica, nos pacientes suspeitos de infecção por poliomielite.

No final de 1964, o laboratório foi em parte destinado a pesquisas sobre vírus herpes, e com isso ficou bastante prejudicado o seu papel como o mais importante centro de enterovírus no país. Apesar das restrições impostas pelo regime militar, foram mantidos os serviços de diagnóstico no plano nacional, estudando infecções por enterovírus em Brasília e no Norte do país (Schatzmayr et al., 1966), além do Rio de Janeiro e regiões próximas, em apoio a ações de controle da doença.

Outra importante contribuição dessa fase de trabalho no IOC consistiu no trabalho, pioneiro no país, de formulação final da vacina oral trivalente contra a poliomielite, a partir dos concentrados importados, utilizando-se a sacarose como estabilizador do produto. A vacina trivalente era então titulada e distribuída para todo país, para atender às campanhas estaduais de vacinação.

Com as dificuldades impostas para o desenvolvimento das atividades do Laboratório de Enterovírus do IOC e para se manter o fluxo de informações sobre poliomielite no estado do Rio de Janeiro, onde continuavam a ocorrer casos clínicos atendidos principalmente 
no Hospital Jesus, o IOC colaborou na montagem de um laboratório de virologia no então Instituto Pasteur, hoje Noel Nutells, onde tiveram prosseguimento os trabalhos sobre a doença (Schatzmayr et al., 1966).

A partir de outubro de 1967, criou-se um Laboratório de Virologia no Departamento de Ciências Biológicas da ENSP, no qual se reiniciaram os trabalhos sobre enterovírus em Manguinhos. As linhas de pesquisa desenvolvidas incluíram a avaliação dos casos de poliomielite internados no Hospital Jesus (Schatzmayr et al., 1968) e de manipulação de células em cultura com o uso de produtos naturais para a sua manutenção (Schatzmayr et alii, 1970).

Nessa fase, na ENSP, realizaram-se ainda vários estudos sobre poliomielite, alguns pioneiros no país, como a demonstração, no nível de campo, da necessidade de se aumentar a quantidade de partículas de tipo 3 na vacina, o que veio a acontecer anos mais tarde, como já foi assinalado, pelo surgimento, no Nordeste, de casos clínicos causados por esse sorotipo em pessoas vacinadas. Também implantou-se, pela primeira vez no país, a pesquisa de vírus em água e em esgotos (Homma et al., 1974), tecnologias que foram repassadas para outros laboratórios, em particular a Cetesb, em São Paulo. Algumas das tecnologias desenvolvidas eram originais, como um sistema de filtração contínua para coleta de água do mar, com concentração simultânea em filtro de lã de vidro.

Realizaram-se então os primeiros estudos de campo sobre os níveis de poluição por vírus nas baías de Guanabara (Homma et alii, 1975) e de Santos (Schatzmayr, 1975). Com essas tecnologias, posteriormente avaliaram-se coleções de água e esgoto em comunidades vacinadas pela vacina oral e pesquisou-se a possível presença de vírus selvagens no esgoto, em áreas suspeitas de sua circulação, em especial no estado de São Paulo.

Em 1977, o Laboratório de Virologia da ENSP foi transferido para o IOC, voltando a atuar como o laboratório central para enterovírus do Ministério da Saúde, sendo credenciado, em 1980, pela portaria ministerial número 346 como Centro Nacional de Referência para Enterovírus (CRNE), e posteriormente pela Opas/Organização Mundial de Saúde (OMS), como Centro Colaborador para Enterovírus. Em setembro do mesmo ano ocorreu o I Encontro Nacional sobre o Diagnóstico de Enterovírus, organizado pelo CRNE, para padronização de técnicas e definição do fluxo de informações entre todos os laboratórios de poliomielite do país. A esse encontro seguiram-se vários outros, nacionais e internacionais, com a participação de membros da Fiocruz, inclusive epidemiologistas da ENSP, para avaliação constante do programa.

Ainda em 1980, com o apoio do Instituto Pasteur, de Paris, foi introduzida no Brasil a técnica de diferenciação intratípica, utilizandose anticorpos monoclonais capazes de distinguir como vacinais ou selvagens os poliovírus isolados dos casos suspeitos de poliomielite 
(Schatzmayr et al., 1985). O método foi utilizado até 1988, sendo substituído pela técnica de hibridização molecular — Dot-blot (DaSilva et alii, 1991; Filippis et alii, 1994), desenvolvida no Laboratório de Virologia Molecular do Centers for Disease Control (CDC) de Atlanta, para ser utilizada por todos os laboratórios de referência credenciados pela Opas/OMS.

A nova metodologia foi fundamental para o programa de erradicação, porque além de ter sido padronizada para ser utilizada por toda a rede credenciada, permitia afirmar com segurança a origem das amostras de poliovírus isolados, viabilizando a futura certificação da erradicação da circulação das amostras selvagens no país e em toda a região das Américas. Em 1991, foi introduzida a técnica da transcrição reversa da reação em cadeia da polimerase (RT-PCR), que permite a detecção do genoma viral mesmo quando presente em pequenas quantidades, além da identificação de seu sorotipo e o seu caráter vacinal ou selvagem (Yang et alii, 1997).

O CRNE estudou, na ocasião, um importante surto de meningite viral (Schatzmayr et alii, 1978) e avaliou, por anticorpos monoclonais, amostras de vírus excretadas após vacinação oral, o que demonstrou diferentes níveis de afinidade, sugerindo modificações em epítopos das amostras, após a replicação nos vacinados. Outras técnicas utilizadas para a diferenciação intratípica de amostras incluíram a de mapeamento de fragmentos genômicos em gel de acrilamida, aplicada em escala limitada (Da-Silva et alii, 1987), e o seqüenciamento de nucleotídeos, que teve uma ampla aplicação não somente no programa de erradicação da poliomielite, como em linhas de pesquisa que analisaram as amostras de poliovírus (Da-Silva et alii, 1990b; Friedrich et alii, 1996a, 1996b, 1995a, 1995b) excretadas por vacinados. Desde 1989, o CRNE realiza o diagnóstico laboratorial da poliomielite não somente para o Brasil mas também o Peru e a Bolívia, analisando centenas de espécimens enviados anualmente de casos suspeitos e seus contatos.

A Fiocruz também participou ativamente na formação de recursos humanos, treinando técnicos da rede de laboratórios regionais e internacionais e estudantes de nível superior e nível médio. Consultorias nacionais e internacionais foram igualmente prestadas, destacando-se consultorias a laboratórios e programas de vacinação nas Américas, na África e na Ásia.

O CNRE continua a exercer plenamente suas funções, mesmo após a erradicação da poliomielite nas Américas, tendo em vista a existência de casos de paralisia associadas à vacinação (Friedrich et alii, 1995a, 1995b, 1995c) e a necessidade de se avaliar o papel de outros enterovírus, como o enterovírus 71 , na geração de casos de paralisias flácidas (Da-Silva et alii, 1990a) e sobretudo pela existência de casos de poliomielite causada por vírus selvagem em extensas áreas dos continentes africano e asiático, onde foram confirmados, 
entre 1996 e 2001, 26.241 casos (OMS, 2002). Existe, assim, o real risco da reintrodução de vírus selvagens no Brasil, a partir dessas áreas, tal como ocorreu no Canadá (MMWR, 1993). Dentre as contribuições mais importantes do grupo da Fiocruz, cabe assinalar a caracterização genômica dos poliovírus de origem vacinal isolados no Brasil.

Embora a vacina oral contra a poliomielite tenha sido fundamental para a erradicação do poliovírus selvagem no Brasil, sabe-se que ela pode, ainda que raramente, causar quadros de paralisia flácida. A introdução da técnica de seqüenciamento nucleotídico, no ano de 1990, permitiu confirmar a origem vacinal dos vírus isolados de casos raros de poliomielite surgidos após o ano de 1989, quando o último poliovírus selvagem havia sido identificado. Além dessa técnica confirmar a existência de casos de poliomielite associados à vacina, ela também permitiu identificar modificações genômicas, tais como mutações e recombinação nos poliovírus de origem vacinal, isolados de casos associados à vacina (Friedrich et alii, 1996a, 1995a, 1995b). Essas modificações genômicas ocorrem durante a replicação dos vírus vacinais nos indivíduos vacinados. Dentre as mutações observadas, foram identificadas algumas, conhecidas por aumentarem a neurovirulência das cepas vacinais.

Avaliou-se ainda a relação da vacina com outros efeitos colaterais neurológicos raros, tais como meningite, encefalite, mielite transversa, síndrome de Guillain-Barré, paralisia facial e outras paralisias transitórias (Friedrich, 1997), relatando-se, em vários estudos (Filippis et alii, 1994; Friedrich et alii, 1996c, 1995b, 1995c, 1995d), o isolamento de poliovírus de origem vacinal de indivíduos com esses quadros neurológicos. Os estudos realizados confirmaram a origem vacinal desses vírus e também atestaram a existência de mutações no genoma conhecidas por aumentarem a neurovirulência.

As modificações genômicas observadas em poliovírus de origem vacinal isolados no Brasil também foram descritas em outros estudos em indivíduos vacinados saudáveis (Macadam et alii, 1989), sugerindo que fatores relacionados ao hospedeiro também são importantes na susceptibilidade ao desenvolvimento de doenças associadas ao poliovírus (Friedrich, 1997). Mais recentemente, amostras de enterovírus isoladas durante sete anos de quadros respiratórios agudos foram analisadas em projeto de colaboração entre os laboratórios de vírus respiratórios e rnterovírus do Departamento de Virologia (Portes et alii, 1998).

\section{A contribuição de Bio-Manguinhos}

Em 1981, foi firmado um acordo de cooperação técnica entre os governos do Brasil e do Japão, tendo como objetivo a transferência de tecnologia de produção das vacinas contra a poliomielite e o sarampo. Como parte fundamental do processo de transferência de tecnologia da produção da vacina contra a poliomielite, o Instituto de Tecnologia 
em Imunobiológicos Bio-Manguinhos, da Fiocruz, recebeu a colaboração do Departamento de Virologia do IOC, para o estabelecimento e a organização do Laboratório de Controle de Qualidade da Vacina Oral contra a Poliomielite.

Nesse contexto, vários profissionais de Bio-Manguinhos e do IOC estiveram no Japão, para realizar treinamento específico em todas as atividades envolvendo o controle de qualidade da vacina, incluindo testes in vitro e in vivo, testes de neurovirulência da vacina em macacos, além das etapas de produção do antígeno viral e da formulação e envase da vacina.

O Laboratório de Controle de Qualidade da Vacina, que passou a operar como anexo ao Departamento de Virologia do IOC, realizou, de 1981 a 1983, os testes de potência, esterilidade e toxicidade inespecífica em todos os lotes de vacina importada, para uso em campanhas e na vacinação de rotina. Com a inauguração e a operacionalização do Instituto Nacional de Controle de Qualidade em Saúde (INCQS), a metodologia e o controle dessa vacina foi repassada a esse instituto, passando Bio-Manguinhos a dedicar-se à produção da vacina.

Embora o estabelecimento do ciclo completo para a produção dessa vacina na Fiocruz tenha sido o escopo inicial do acordo de cooperação técnica com o Japão, e embora os técnicos de Bio-Manguinhos tenham sido treinados em todas as etapas de produção e controle de qualidade, a implementação de todo o ciclo de produção mostrou-se muito complexa do ponto de vista técnico e administrativo, especialmente pela crescente dificuldade de importação, a cada ano, de centenas de primatas africanos necessários à produção da massa viral. Considerandose a grande disponibilidade mundial do concentrado viral de alta qualidade e com baixo preço, concluiu-se que o projeto era economicamente desfavorável.

Mas levando em conta que é estrategicamente importante para o país o estabelecimento de parte do ciclo de produção, Bio-Manguinhos iniciou o desenvolvimento da formulação da vacina a partir de concentrado de vírus importado; além disso, analisou e definiu a composição de um melhor termoestabilizador e aperfeiçoou uma formulação ideal da vacina para o nosso país e outros, de clima tropical.

A estratégia mostrou-se correta, pois, desde 1986, quando da ocorrência de uma epidemia de poliomielite provocada pelo poliovírus tipo 3 na região Nordeste, em população com altas taxas de cobertura vacinal, Bio-Manguinhos disponibilizou em apenas vinte dias formulações de vacina monovalente tipo 3 e trivalente potencializada para o sorotipo 3 , enquanto os produtores externos solicitaram um período de seis meses para modificar sua programação de produção para atender à solicitação do Brasil.

Com a aplicação da vacina e a avaliação da resposta a cada uma das formulações, foi possível não só o controle da epidemia no Nordeste (Patriarca et alii, 1991), bem como a redefinição da 
formulação da vacina com seiscentas mil partículas infectantes do tipo 3. A formulação foi adotada pela Opas nos finais da década de 1980 para todos os países da América Latina e hoje é adotada pela OMS para todos os países de clima tropical. A formulação passou a ser adotada igualmente pelos produtores privados que fornecem vacinas para regiões tropicais.

Desde que iniciou a produção da vacina oral contra a poliomielite, a partir de concentrado viral importado, Bio-Manguinhos disponibilizou para o Programa Nacional de Imunizações (PNI) mais de 150 milhões de doses. Com a intensificação das ações para a erradicação do poliovírus selvagem do mundo, especialmente da Índia e do continente africano, o Fundo das Nações Unidas para a Infância (Unicef) vem necessitando adquirir quantitativos da vacina superiores à capacidade instalada para o processamento final, tornando-se, portanto, de suma importância para o PNI que Bio-Manguinhos forneça-a para manutenção de nossos programas anuais de vacinação em massa.

A incorporação da tecnologia de controle de qualidade e produção dessa vacina, sem dúvida alguma também permitiu desdobramentos tecnológicos importantes, contribuindo para o aperfeiçoamento de outras vacinas virais produzidos por Bio-Manguinhos.

Em resumo, a participação da Fiocruz foi fundamental para o programa de erradicação do vírus selvagem da poliomielite nas Américas, porque monitorou com alto rigor científico os vários segmentos propostos para o programa, desde a produção e o controle da vacina distribuída para a população, a consultoria e o treinamento de pessoal, até o isolamento e a análise molecular dos vírus circulantes na região, permitindo assim comprovar a eliminação do vírus selvagem não somente no Brasil como, finalmente, em toda a região das Américas.

\section{REFERÊNCIAS BIBLIOGRÁFICAS}

Ayrosa-Galvão, A. L. N. et al. 1955

Brito Bastos, N. C. et alii 1974

Da-Silva, E. E. et alii 1996

Da-Silva, E. E. et alii 1991

Da-Silva, E. E. et alii $1990 \mathrm{a}$
'Alguns dados epidemiológicos sobre a poliomielite no interior do estado de São Paulo'. Rev. Hosp. das Clínicas, vol. 10, nº 4, pp. 311-21.

'Antipoliomyelitis program in Brazil: a serologic study of immunity levels'. Boletim Repartição Sanitária Pan-americana, vol. 8, n 54-65.

'Role of enterovirus 71 in acute flaccid paralysis after the eradication of poliovirus in Brazil'. Emergent Infectious Diseases, nº 2, pp. 231-3.

'Oligonucleotide probes for the specific detection of the wild poliovirus types 1 and 3 endemic to Brazil'. Intervirology, no 32, pp. 149-59.

'Evidence of enterovírus 71 infections in Brazil'.

Memórias do Instituto Oswaldo Cruz, no 85, pp. 131-2. 
Da-Silva E. E. et alii 1990b

Da-Silva E. E. et alii 1987

Da-Silva, E. E. et alii 1980

Enders, J. F. et alii 1949

Filippis, A. M. B. et alii 1994

Friedrich, F. 1997

Friedrich, F. et alii $1996 \mathrm{a}$

Friedrich, F. et alii 1996b

Friedrich, F. et alii 1996c

Friedrich F. et alii $1995 \mathrm{a}$

Friedrich F. et alii 1995b

Friedrich, F. et alii $1995 \mathrm{c}$

Friedrich. F. et alii $1995 \mathrm{~d}$

Homma. A. et alii 1975

Homma, A. et al. 1974

Kilpatrick, D. R. et alii 1998

Lima Filho, J. et al. 1993

Macadam, A. J. et alii 1989

Meilman, I. et alii 1988
'Nucleotide sequences of the VP1 capsid proteins of wild poliovirus types 1 and 3 from epidemic areas of Brazil'. Brazilian Journal of Medical and Biological Research, n 23, pp. 1-5.

'Studies on type 1 poliovirus isolated in Brazil by electrophoresis and monoclonal analysis'. Memórias do Instituto Oswaldo Cruz, n. 82, pp. 133-5.

'Evidence of enterovirus 71 infections in Brazil'.

Memórias do Instituto Oswaldo Cruz, no ${ }^{\circ}$, pp. 131-2.

'Cultivation of the Lansing strain of poliomyelitis virus in cultures of various human embryonic tissues'. Science, n⿳⺈ 109, p. 85.

'Intratypic differentiation of polioviruses isolated from suspected cases of poliomyelitis in Brazil during the period of 1990 to 1993'.

Memórias do Instituto Oswaldo Cruz, no 89, pp. 513-8.

'Rare adverse events associated with oral poliovirus vaccine in Brazil'. Brazilian Journal of Medical and Biological Research, nº. 30, pp. 695-703.

'Type 2 poliovirus recombinants isolated from vaccine-associated cases and from healthy contacts in Brazil'. Acta Virologica, no 40, pp. 27-33.

'Poliovirus type 1 isolated from a vaccine-associated case of paralytic poliomyelitis in Brazil'.

Brazilian Journal of Medical and Biological Research, no 29, pp. 15-8.

'Temporal association between the isolation of Sabin-related poliovirus vaccine strains and the Guillain-Barré syndrome'. Revista do Instituto de Medicina Tropical de São Paulo, no 38, pp. 55-8.

'Genomic characterization of type 2 polioviruses isolated from vaccine-associated cases in Brazil'. Brazilian Journal of Medical and Biological Research, no 28, pp. 733-42.

'Genomic characterization of type 3 polioviruses isolated from vaccine-associated poliomyelitis cases in Brazil'.

Brazilian Journal of Medical and Biological Research, n. 28, pp. 195-200.

'Genomic characterization of type 1 Sabin-related polioviruses isolated in Brazil'. Acta Virologica, no 39, pp. 23-9.

'Sabin-related poliovirus vaccine strains isolated from transverse myelitis cases in Brazil'.

Revista do Instituto de Medicina Tropical de São Paulo, no 37, pp. 543-5.

'Viral pollution evaluation of the Guanabara Bay'.

Revista do Instituto de Medicina Tropical de São Paulo, no 17, pp. 140-5.

'Quantitative method of viral pollution determination for large volumes of water using ferric hydroxide gel impregnated on the surface of glassfibre cartridge filter'. Memórias do Instituto Oswaldo Cruz, nº 70, pp. 31-41.

'Serotype-specific identification of polioviruses by PCR using primers containing mixed-base or deoxyinosine residues at positions of codon degeneracy'. Journal of Clinical Microbiology, no 36, pp. 352-7.

'Poliomielite - passado e presente'. Bibliografia do Ministério da Saúde.

'Reversion of the attenuated and temperature-sensitive phenotypes of the Sabin type 3 strain of poliovirus in vaccinees'.

Virology, no 172 , pp. 408-14.

'Aspectos clínicos da infecção'. Em C. R. Oliveira et al. (org.), Bases técnicas para a erradicação da transmissão autóctone da poliomielite. $2^{\underline{a}}$ ed., Brasília, Centro de Documentação do Ministério da Saúde, pp. 1-68. 
MMWR - Morbidity Mortality Weekly Report maio 1993

OMS - Organização

Mundial de Saúde 2002

Patriarca, P. A. et alii 1991

Portes, S. A et alii 1998

Risi Jr, J. B.

1984

Schatzmayr, H. G. et alii

1986

Schatzmayr, H. G. et al. 1985

Schatzmayr, H. G. et alii

1978

Schatzmayr, H. G.

Schatzmayr, H. G. et alii

Schatzmayr, H. G. et alii

Schatzmayr, H. G. et aIii

1970

Schatzmayr, H. G. et al.

Schatzmayr, H. G. et al.

1966

Schatzmayr, H. G.

Schatzmayr, H. G. et al.

Schatzmayr, H. G.

1964

Schatzmayr, H. G. et alii

1962
'Isolation of wild poliovirus type 3 among members of a religious community objecting to vaccination-Alberta, Canada, 1993'.

MMWR, vol. 42, nำ 17 , pp. 337-9

'Progress towards global poliomyelitis eradication, 1999'.

Weekly Epidemiological Record, nำ 75, pp. 134-43.

'Factors affecting the immunogenicity of oral poliovirus vaccine in developing countries: review'. Reviews Infectious Diseases, no $¹ 3$, pp. 926-39.

'Enteroviruses isolated from patients with acute respiratory infections during seven years in Rio de Janeiro (1985-1991)'.

Revista do Instituto de Medicina Tropical de São Paulo, nº 40, pp. 337-42.

'The control of poliomyelitis in Brazil'.

Reviews Infectious Diseases, no 6, pp. 400-3.

'Serological evaluation of poliomyelitis oral and inactivated vaccines in a low-income population at Rio de Janeiro, Brazil.' Vaccine, no 4, pp. 111-3.

'Emprego de reação imunoenzimatica na determinação do caráter genético de amostras de poliovírus'. Memórias do Instituto Oswaldo Cruz, nº 80, pp. 23-4.

'Isolation of ECHO 9 vírus from cases of aseptic meningitis'.

Revista de Microbiologia de São Paulo, no 9, pp. 210-1.

Estudos sobre o isolamento de vírus da água do mar. Dissertação de livredocência em virologia, Rio de Janeiro, Universidade Federal Fluminense.

'Anticorpos para enterovírus na localidade de Ferreira Gomes,

no territorio federal do Amapá'.

Revista da Sociedade Brasileira de Medicina Tropical, nํㅡ, pp. 19-21.

'Poliomyelitis: epidemiological aspects in Rio de Janeiro (Guanabara State) and adjacent areas in the period from 1961 to 1970 (1972)'. Memórias do Instituto Oswaldo Cruz, n 70, pp. 207-20.

'O uso de água de coco verde para o cultivo de células animais'.

Revista Brasileira de Biologia, no 30, pp. 97-100.

'Levantamento epidemiológico e virológico de casos suspeitos de poliomielite no Hospital Estadual Jesus no período de janeiro de 1967 a março de 1968'. Revista da Sociedade Brasileira de Medicina Tropical, no 2, pp. 229-35.

'Poliovírus tipo 1 em casos de poliomielite aguda no Estado da Guanabara'. Revista do Instituto de Medicina Tropical de São Paulo, no 8, pp. 246-8.

'Estudos sobre algumas amostras de Coxsackie A em cultura de tecidos'. Revista Brasileira Biologia, no 25, pp. 411-7.

'Investigações sobre infecções por enterovírus no Distrito Federal'. Memórias do Instituto Oswaldo Cruz, no 64, pp. 125-30.

'Observações sobre o uso de células de pulmão embrionário humano na rotina et al. de diagnostico de enterovírus'. Boletim do Instituto de Puericultura da Universidade Brasil, no 21, pp. 139-42.

'Uma técnica simples para o isolamento de vírus de material contaminado. Estudos preliminares'. O Hospital, no 62, pp. 977-86. 
HERMANN G. SCHATZMAYR ET ALII

Scorzelli, J. A. 'A poliomielite no Rio de Janeiro: estudo epidemiológico'.

1966

Arquivos de Higiene, vol. 22, $\mathrm{n}^{\circ}$ 1, pp. 65-176.

Silveira, S. C. T.

1983

Evolução e controle da poliomielite no Rio Grande do Norte

no período de 1977 a 1983. Dissertação de mestrado, Rio de Janeiro,

Escola Nacional de Saúde Pública, Fundação Oswaldo Cruz.

Von Hubinger, M. G.

1975

A poliomielite no Rio de Janeiro de 1907 a 1974. Tese de doutoramento,

Rio de Janeiro, Instituto de Microbiologia, Universidade Federal do Rio de Janeiro. Higiene, vol. 22, nº 1, pp. 65-176.

Yang et alii

1997

'Genotype-specific RNA probes for direct identification of wild polioviruses

by blot hybridization'. Journal of Clinical Microbiology, nº 35, pp. 2834-40.

Recebido para publicação em abril de 2001.

Aprovado para publicação em janeiro de 2002. 